\title{
Edukasi pencegahan sindrom kelelahan (burnout) pada karyawan pertamina MOR II Palembang
}

\author{
Veny Larasati ${ }^{1}$, Bintang Arroyantri ${ }^{2}$, Ziske Maritska ${ }^{3}$, Nita Parisa ${ }^{4}$ Diyaz Syauki \\ Ikhsan $^{5}$
}

\author{
${ }^{1}$ Bagian Histologi, Fakultas Kedokteran, Universitas Sriwijaya \\ ${ }^{2}$ Bagian Ilmu Kedokteran Jiwa, Fakultas Kedokteran, Universitas Sriwijaya \\ ${ }^{3}$ Bagian Biologi Kedokteran, Fakultas Kedokteran, Universitas Sriwijaya \\ ${ }^{4}$ Bagian Farmakologi Kedokteran, Fakultas Kedokteran, Universitas Sriwijaya \\ ${ }^{5}$ Bagian Ilmu Kedokteran Jiwa, Fakultas Kedokteran, Universitas Sriwijaya \\ E-mail: bintangarroyantri@gmail.com²
}

\begin{abstract}
Abstrak
Sindrom kelelahan (burnout) adalah sindrom yang muncul akibat stres interpersonal yang berkepanjangan akibat kerja. Sindrom kelelahan (burnout) ini dapat juga dikatakan sebagai kelelahan psikologis akibat kerja. Hal ini bisa terjadi akibat tuntutan yang tinggi dari perusahaan untuk memberikan hasil kerja yang optimal yang tidak mampu ditoleransi oleh karyawan. Ada tiga hal yang dapat memicu terjadinya sindrom kejenuhan ini, yaitu beban kerja yang berlebihan, pengabaian terhadap hasil kerja dan perasaan kurang dihargai di tempat kerja. Berdasarkan survey yang dilakukan di Amerika, penyebab stres terbesar adalah karena beban kerja yang berlebihan yaitu sekitar $46 \%$, dan 1 dari 5 karyawan mengalami sindrom kejenuhan (burnout). Di Indonesia, hasil survey menyebutkan bahwa sekitar 64\% karyawan mengalami peningkatan kelelahan akibat kerja, dan sekitar 20\% karyawan percaya bahwa kelelahan psikologis menjadi penyebab tidak masuknya karyawan dengan alasan sakit di perusahaan. Pengabdian masyarakat ini dilakukan atas permintaan dari Perusahaan Pertamina Palembang. Sindrom kejenuhan (burnout) menjadi masalah yang serius bagi karyawan dan perusahaan. Jika tidak segera diatasi akan memicu timbulnya gangguan psikologis yang cukup berat pada karyawan seperti penurunan produktifitas, penarikan diri dari tempat kerja, depresi bahkan kecemasan, yang kemudian pada akhirnya bisa berdampak negatif bagi perusahaan. Untuk itulah diperlukan adanya monitoring dan evaluasi terkait dengan kondisi psikologis karyawan yang berkala.
\end{abstract}

Kata kunci: Sindrom Kelelahan, Karyawan, Pertamina

\begin{abstract}
Education for Preventing Burnout Syndrome to Pertamina MOR II Palembang workers. Burnout is a syndrome that occurs due to prolonged interpersonal stress due to work. Burnout can also be described as psychological fatigue caused by work. This can occur due to the high demands of the company to provide optimal work results that the employees cannot tolerate. There are three things that can trigger this syndrome, namely excessive workload, neglect of work results and feelings of underappreciation at work. Based on a survey conducted in America, the main reason of stress was due to excessive workload, 1 in 5 employees experienced burnout syndrome which is around 46\%, and in Indonesia, the survey results showed that around $64 \%$ of employees experienced increased fatigue due to work, and around 20\% of employees believed that psychological fatigue is the cause of the absence of employees due to illness in the company. This community service is carried out at the request of the PERTAMINA Palembang Company. Burnout syndrome is a serious problem for employees and employers. If not addressed properly, it will lead to serious psychological problems for employees such
\end{abstract}


as decreased productivity, withdrawal from work, depression and even anxiety, which in turn can have a negative impact on the company. For this reason, it is necessary to have monitoring and evaluation related to the psychological condition of employees on a regular basis.

Keywords: Burnout, Employee, Pertamina

\section{PENDAHULUAN}

Sindrom kelelahan (burnout) adalah sindrom yang muncul akibat stres interpersonal yang berkepanjangan akibat kerja. Sindrom kelelahan (burnout) ini dapat juga dikatakan sebagai kelelahan psikologis akibat kerja. ${ }^{1}$ Menurut Préat (2000) sindrom kelelahan tidak hanya berhubungan dengan lingkungan kerja tertentu, usia atau jenis kelamin. Kejadian burnout dilaporkan terjadi pada beberapa jenis pekerjaan yang berbeda seperti pekerja sosial, penasehat, guru, perawat, pekerja laboratorium, terapis bicara, dokter, dokter gigi, polisi, sipir penjara, pramugari, manajer bahkan ibu rumah tangga, pelajar dan pengangguran.

Sindrom kelelahan merupakan kondisi stress kronis di lingkungan kerja yang tidak tertangani dengan baik, ditandai dengan kelelahan, depersonalisasi (negativisme dan sikap sinis) dan penurunan performa kerja. Beberapa faktor penyebab terjadinya burn out yaitu stres berkepanjangan yang tidak ditangani dengan baik, ketidaksesuaian pekerja dan lingkungan kerjanya dan kesenjangan antara harapan dan kenyataan. Saat ini dipercaya bahwa kondisi stress negatif (distress) merupakan penyebab terpenting terjadinya burnout. Selain itu, kondisi rutinitas sehari-hari yang melelahkan dan kekecewaan terhadap sesuatu yang diharapkan juga menjadi penyebab terjadinya sindrom kelelahan. ${ }^{2}$

Sindrom kelelahan yang terjadi pada karyawan dapat juga disebabkan karena interaksi dengan klien yang intens. Hal ini dapat terjadi pada staf professional yang sering berhubungan dengan klien atau pekerjaan-pekerjaan yang berhubungan dengan pelayanan masyarakat. Sindrom kelelahan yang berhubungan dengan hubungan staf-klien ini dapat disebabkan oleh stres emosional yang tinggi pada pekerjaan atau komplain yang sering disampaikan oleh klien sehingga staf kehilangan simpati pada kliennya. ${ }^{3}$ Menurut penelitian yang dilakukan oleh Dolgova (2016), munculnya gejala burnout di perkantoran 
berhubungan dengan aktivitas professional pekerjaannya apakah berinteraksi dengan orang lain atau tidak. ${ }^{4}$ Sindrom kelelahan juga dapat terjadi akibat hubungan antara sesama pekerja, atasan atau bawahan.

Sindrom kelelahan yang terjadi pada karyawan merupakan hal yang penting untuk menjadi perhatian karena dapat menimbulkan beberapa gejala yang multidimensi meliputi psikiatris, psikosomatis, somatis dan sosial. Gejala psikiatris yang dapat terjadi yaitu gangguan konsentrasi dan memori (kurang presisi, kurang terorganisasi), perubahan semangat kerja dan kepribadian (hilang minat, sinis dan agresif). Kondisi berat akibat sindrom kelelahan ini meliputi kecemasan dan gangguan depresif yang dapat berakhir pada kejadian bunuh diri. Selain itu, kondisi adiksi alkohol dan obat-obatan terlarang juga dilaporkan berhubungan dengan burnout. Gejala somatik yang dapat disebabkan oleh burnout antara lain sakit kepala, gangguan gastrointestinal, gangguan kardiovaskular seperti takikardi, aritmia dan hipertonia. Gangguan psikosomatik meliputi gangguan tidur, gangguan seksual, konsumsi alkohol dan obat-obatan terlarang. Gejala sosial yang dapat terjadi akibat sindrom kelelahan yaitu menarik diri dari lingkungan sosial dan seringkali tidak masuk kerja. ${ }^{2}$

Mengingat banyaknya efek buruk yang dapat ditimbulkan bagi para pekerja akibat sindroma kelelahan ini jika tidak ditangani dengan baik, dan bagi perusahaan yang menaungi pekerja, kondisi burnout pada akhirnya akan sangat merugikan karena mengurangi produktivitas kerja para karyawan dan tidak tercapainya target kinerja yang diinginkan oleh perusahaan, maka edukasi tentang sindroma kelelahan akibat pekerjaan dan cara mengatasinya kepada karyawan sangatlah penting untuk dilakukan dalam upaya mempertahankan produktivitas para karyawan, mencegah terjadinya efek negatif pada kondisi fisik dan mental para karyawan. Perusahaan Pertamina MOR II Palembang memberikan perhatian cukup besar pada kondisi Kesehatan mental para pegawai sehingga menginisiasi program pengabdian masyarakat yang melibatkan beberapa dosen dari 
Fakultas Kedokteran Universitas Sriwijaya untuk mengedukasi para pegawai tentang cara mengatasi sindrom kelelahan yang mungkin ditimbulkan akibat beban kerja.

\section{TINJAUAN PUSTAKA}

Istilah "burnout" atau sindrom kelelahan diperkenalkan pertama kali oleh Freuden-berger pada tahun 1974 untuk menggambarkan kelelahan yang dialami pekerja Kesehatan mental di tempat kerja. ${ }^{5}$ Penelitian yang dilakukan oleh Yong (2020) pada pekerja tambang di Cina menunjukkan hasil bahwa terdapat hubungan antara stres yang ditimbulkan di tempat kerja dengan terjadinya sindroma kelelahan (burnout), depresi dan hipertensi. ${ }^{6}$

\section{Dimensi}

Sindrom Kelelahan (burnout) dapat dibagi atas tiga dimensi, yaitu kelelahan emosional (emotional exhaustion), depersonalisasi (depersonalization), penurunan pencapaian prestasi pribadi. Kelelahan emosional merupakan ciri utama serta menjadi manifestasi paling jelas dari burnout. Kelelahan emosional adalah perasaan kelelahan yang dialami di tempat kerja. Ketika seseorang mengalami exhaustion maka mereka akan merasakan energinya seperti terkuras habis dan ada perasaan "kosong" yang tidak dapat teratasi lagi."

Depersonalisasi merupakan upaya untuk memberi jarak antara diri sendiri dan orang lain melalui tindakan menghiraukan kualitas yang membuat mereka unik dan menarik. Fenomena ini dapat terjadi sebagai proses penyeimbangan antara tuntutan pekerjaan dan kemampuan individu. Manifestasi depersonalisasi berupa sikap sinis terhadap orang-orang yang berada dalam lingkup pekerjaan disertai kecenderungan menarik diri serta mengurangi keterlibatan dalam bekerja. Perilaku tersebut dikaitkan dengan upaya proteksi diri dari perasaan kecewa, karena penderita menganggap bahwa dengan berperilaku seperti itu, maka mereka akan terhindar dari ketidakpastian dalam pekerjaan. Penurunan pencapaian pribadi ditandai dengan ketidakpuasan terhadap diri 
sendiri. Kondisi tersebut menyebabkan penderita mengalami kesulitan untuk meningkatkan prestasi pribadi di masa depan. ${ }^{7}$

\section{Diagnosis}

Maslach Burnout Inventory (MBI) merupakan alat ukur diri yang terdiri dari 2 subskala yang berfungsi menilai beberapa aspek dari burnout yaitu kelelahan emosional, depersonalisasi (perasaan negatif ataupun perasaan dan tindakan sinis) dan menurunnya pencapaian personal. Kelelahan emosional, gangguan fungsi kognitif, penurunan pencapaian/ pemenuhan pribadi, peningkatan tanda distress emosional, distress interpersonal, gangguan penampilan perilaku, peningkatan gejala fisik, organizational distress. ${ }^{8}$

Gejala burnout dapat berupa gejala somatik, psikologis, dan perilaku. Gejala somatik dicirikan dengan energi yang rendah dan kelelahan kronik. Gangguan makan (terlalu banyak atau terlalu sedikit) juga dapat ditemukan. Gangguan tidur dapat bermanifestasi dalam bentu ekstrim dari insomnia atau tidur berlebih. Terdapat peningkatan kerentanan terhadap penyakit dan gejala psikosomatis juga ditemukan. Gejala somatik lain adalah peptic ulcer, sakit kepala, demam yang menetap, sakit punggung, tekanan darah tinggi, gangguan gastrointestinal, sesak nafas, masalah kulit. ${ }^{2}$

Gejala psikologis dari sindrom kelelahan (burnout) dicirikan oleh rasa lelah atau depresi dan dapat dibagi menjadi: kelelahan emosional dan kelelahan mental. Perubahan perilaku yang berkaitan dengan pekerjaan berupa penurunan efisiensi kerja (kuantitatif dan kualitatif), datang terlambat, tidak hadir, gangguan hubungan interpersonal didalam pekerjaan. ${ }^{2}$

\section{Tatalaksana dan Pencegahan Burnout}

Pencegahan dan tatalaksana sindrom kelelahan (burnout) perlu dilakukan tindak lanjut agar dampak yang ditimbulkan tidak meluas. Upaya pencegahan yang dapat 
dilakukan meliputi modifikasi lingkungan kerja dan meningkatkan kemampuan individu untuk mengatasi stress. Upaya pencegahan dibagi menjadi tiga level, upaya pencegahan primer dengan menghindari atau menghilangkan faktor-faktor yang menyebabkan burnout dilakukan dengan menyediakan fasilitas kerja yang ergonomis, modifikasi lingkungan kerja, organisasi dan manajemen, upaya pencegahan sekunder dengan deteksi dan intervensi dini bertujuan mengurangi stress dalam pekerjaan dilakukan dengan memberikan training dan edukasi pada para pekerja, upaya pencegahan tersier yaitu berhubungan dengan bagaimana menangani akibat yang ditimbulkan oleh burnout, rehabilitasi dan profilaksis relaps dengan membentuk sistem manajemen yang responsif dan meningkatkan pelayanan kesehatan kerja. ${ }^{9}$

Strategi paling utama dalam mencegah sindroma kelelahan adalah dengan mengurangi stres yang pada umumnya tidak bisa dicapai hanya dengan strategi tunggal. Fleksibilitas dalam bekerja, transparansi dan dialog antar pekerja dan pekerja dengan organisasi sangat dibutuhkan. Hubungan interpersonal yang baik, lingkungan kerja yang aman dan target kerja yang masuk akal merupakan hal-hal yang dapat dilakukan untuk mencegah sindroma kelelahan pada pekerja. ${ }^{9}$

Menurut penelitian yang dilakukan oleh Lambert (2012) kepercayaan (trust) merupakan hal yang sangat penting dalam berorganisasi untuk membangun lingkungan kerja yang sehat. Kepercayaan antara staf, supervisor dan manajemen di suatu lingkungan kerja terbukti dapat mengurangi level sindroma kelelahan. ${ }^{10}$ Sindrom kelelahan cukup sulit untuk dicegah, penekanan pada kerja tim dan memberikan masukan psikologis yang positif merupakan hal yang penting bagi seorang pekerja untuk dapat merasa puas dalam pekerjaannya. Pertukaran posisi dan tanggung jawab karyawan secara berkala dapat menjaga minat dan semangat seseorang dalam bekerja. Akan tetapi, perubahan posisi dan perubahan tanggung jawab kerja ini tidak boleh terlalu sering dan harus memperhatikan kualifikasi pekerja. Selain itu, deteksi awal terhadap tanda-tanda depresi dan komorbiditas merupakan hal yang penting dalam menangani sindrom kelelahan akibat kerja. ${ }^{5}$ 
Penelitian yang dilakukan di Cina pada para pekerja tambang menunjukkan adanya hubungan yang kuat antara kualitas tidur dengan sindroma kelelahan. Kualitas tidur yang baik menurunkan resiko terjadinya burnout sebesar 30\% (OR: 0.70; 95\%CI, 0.60 to $0.82, \mathrm{p}=$ 6.02e-06). Hal ini mengindikasikan bahwa kualitas tidur yang baik dapat menekan angka kejadian burnout dan penyakit-penyakit klinis yang berhubungan dengan burnout. Intervensi yang efektif untuk meningkatkan kualitas tidur para pekerja sangat dibutuhkan untuk mencegah burnout dan meningkatkan kualitas hidup pekerja. ${ }^{11}$

\section{METODE}

Edukasi dan presentasi merupakan metode yang digunakan dalam melakukan kegiatan ini. Sebelum dimulai, akan dilakukan pretest terlebih dahulu untuk mengetahui tingkat pengetahuan karyawan mengenai sindrom kelelahan (burnout), selanjutnya akan dilakukan edukasi dan sesi diskusi. Setelah itu, baru dilakukan penapisan untuk mengetahui tingkat kelelahan yang dialami oleh karyawan.

\section{HASIL DAN PEMBAHASAN}

Kegiatan edukasi dilaksanakan pada karyawan Pertamina Marketing Operation Region II (MOR II) Palembang. Sebagian besar bekerja di kantor pada fungsi tehnik, keuangan, legal, IT, medikal, humas dan SDM. Acara dihadiri oleh 96 karyawan yang sebagian besar terdiri dari laki-laki $(77,08 \%)$.

Tabel 1. Karakteristik Sosiodemografi

\begin{tabular}{ccc}
\hline Jenis kelamin & $\mathbf{n}$ & \% \\
\hline Laki-laki & 74 & 77,08 \\
Perempuan & 22 & 22,91 \\
\hline
\end{tabular}


Kegiatan diawali dengan pemberian pretest tentang pemahaman para karyawan terhadap sindroma burnout. Pretest dilakukan untuk mengetahui sejauh mana pemahaman awal para karyawan terhadapat terjadinya sindroma burnout dalam pekerjaan, bagaimana cara mendeteksinya dan bagaimana penanganannya. Kegiatan dilanjutkan dengan edukasi yang disampaikan oleh dokter ahli Kesehatan jiwa, dr.Syarifah Aini, SpKJ yang menjelaskan secara detail tentang fenomena burnout yang dapat terjadi pada karyawan, memberikan pemahaman yang benar tentang cara mendeteksi dan menangani sindroma burnout jika mengalaminya dan kapan harus mencari pertolongan profesional. Kemudian diakhiri dengan sesi tanya jawab dan diskusi untuk memperdalam pemahaman peserta terhadap topik yang disampaikan narasumber. Sebagian besar peserta aktif terlihat aktif dalam sesi ini dengan menyampaikan berbagai macam pertanyaan kepada narasumber. Dokumentasi kegiatan ditampilkan pada Gambar 1.

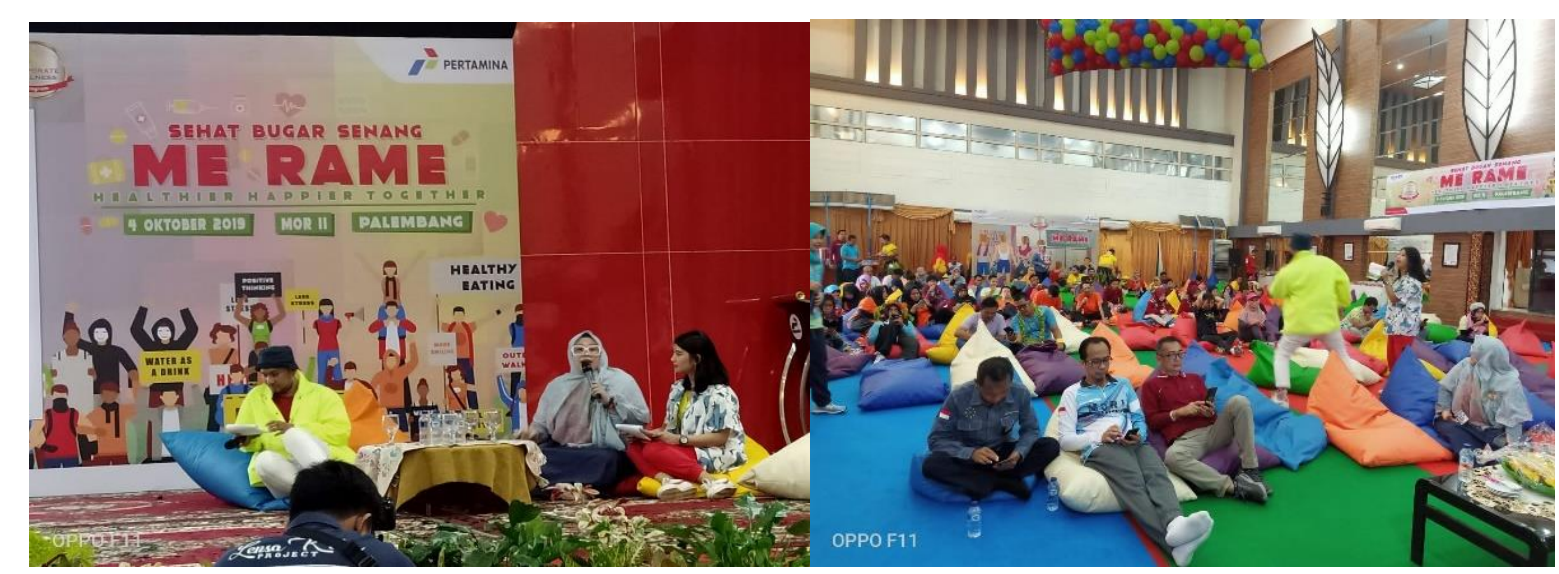

Gambar 1. Suasana kegiatan pengabdian masyarakat pada karyawan

Pengabdian masyarakat ini selain bertujuan untuk mengetahui pengetahuan karyawan mengenai sindrom kelelahan (burnout) pada karyawan sekaligus memberikan edukasi mengenai tanda dan gejala serta penanganan awalnya. Melalui kegiatan ini diharapkan dapat meningkatkan kemampuan para karyawan dalam mendeteksi adanya sindrom kelelahan (burnout) pada diri mereka sendiri dan mampu melakukan 
penatalaksanaan awal serta memberikan informasi kepada perusahaan mereka mengenai gangguan ini.

\section{SIMPULAN}

Sindroma kelelahan atau burnout merupakan hal yang dapat terjadi pada seseorang akibat stres pekerjaan, seringkali tidak terdeteksi dan tidak diperhatikan sehingga dapat menimbulkan gejala-gejala merugikan baik bagi pekerja maupun bagi perusahaan tempat para pekerja bernaung. Pengetahuan dan pemahaman yang baik tentang sindroma kelelahan ini merupakan hal yang sangat penting bagi para pekerja dan pengambil kebijakan di suatu perusahaan untuk mencegah terjadinya efek buruk yang ditimbulkan oleh sindroma kelelahan ini.

\section{Ucapan Terima Kasih}

Penulis mengucapkan terimakasih yang sebesar-besarnya kepada semua pihak yang telah terlibat dalam kegiatan pengabdian masyarakat ini sehingga dapat terlaksana dengan baik, terutama kepada Fungsi Medical PT Pertamina MOR II Palembang, Rektor Universitas Sriwijaya, Fakultas Kedokteran Universitas Sriwijaya, Ketua Pusat Pelayanan dan Pengembangan Lembaga Penelitian dan Pengabdian (PPP-LPPM) UNSRI, Dekan FK UNSRI serta karyawan PT Pertamina MOR II Palembang.

\section{Referensi}

1. Rodrigues H, Cobucci R, Oliveira A, Cabral JV, Medeiros L, Gurgel K, et al. Burnout syndrome among medical residents: A systematic review and meta-analysis. PLoS One. 2018;13(11):1-17.

2. Préat B. Burnout syndrome: A disease of modern societies? Occup Med (Chic Ill). 2000;50(7):512-7.

3. Maslach C. Client Role in Staff Burn-Out. J Soc Issues. 1978;34(4):111-24.

4. Dolgova VI, Rozhkova ON, Bogachev AN, Vorozheykina A V, Ivanova L V. Specipics of emotional burnout in office. 2016;97(22):129-34. 
5. Iacovides A, Fountoulakis KN, Kaprinis S, Kaprinis G. T he relationship between job stress , burnout and clinical depression. 2003;75:209-21.

6. Yong X, Gao X, Zhang Z, Ge H, Sun X, Ma X. Associations of occupational stress with out, depression and hypertension in coal miners of Xinjiang, China : a cross- - sectional study. 2020;1-8.

7. Salvagioni DAJ, Melanda FN, Mesas AE, González AD, Gabani FL, De Andrade SM. Physical, psychological and occupational consequences of job burnout: A systematic review of prospective studies. PLoS One. 2017;12(10):1-29.

8. Kowalski KM, Podlesny A. A study of burnout in accident investigators in the US mining industry. 2002;1(2).

9. Bährer-Kohler S. Burnout for Experts: Prevention in the context of living and working. Burn Expert Prev Context Living Work. 2013;1-257.

10. Lambert EG, Hogan NL, Barton-bellessa SM. Job burnout among correctional staff. 2012;938-57.

11. Gao X, Ma K, Wang H, Gao Q, Lei L, Wang T. Association of sleep quality with job burnout among Chinese coal mine staff: a propensity score weighting analysis. 2019;(June):1-9. 